\title{
10th Dawood and Tanner Study Day Programme
}

7 February saw the 10th Dawood and Tanner Study Day Programme being held at the Wellcome Collection in Euston. The theme of the day was 'Planning for success' focusing on all aspects of restorative dentistry as well as hearing from guest speakers Dr Kevin Lewis and Dr Zoe Laughlin on their chosen subjects.

Dr Andrew Dawood and Dr Susan Tanner are a husband and wife team who for over 25 years have run the highly successful Dawood and Tanner Specialist referral practice in London, renowned for their dental implant and restorative treatments.

The whole team at Dawood and Tanner are passionate about education, providing in-house courses, lectures and seminars. Once a year, they hold their preeminent study day with a selection of well-known and respected invited speakers, along with members of the Dawood and Tanner team.

This year to mark their 10th Study Day, they included a unique event within the programme where they invited three practitioners to share case studies in a PechaKucha style 'Storytelling' format - 20 slides, 20 seconds each slide - three speakers. Each speaker had 20 slides, 20 seconds each slide to discuss a case, whether good or bad, at break-neck speed.

The morning session kicked off to a full house with an introduction from moderator Dawood \& Tanner's Practice Manager Alison Steadward. The first lecture was from Dr Kevin Lewis on managing difficult patients. Kevin described the different ways in which patients can present challenges and seem 'difficult' in their relationship with dentists and other team members. He also provided a range of proven techniques for building rapport with patients and managing their expectations, maximising patient satisfaction and the potential for practice growth while minimising the potential for complaints, litigation and other forms of dento-legal challenge. Delegates were able to recognise why management of 'difficult' patients can sometimes have the effect of making them more 'difficult' and learning some practical tips for recovering difficult situations and patient relationships.

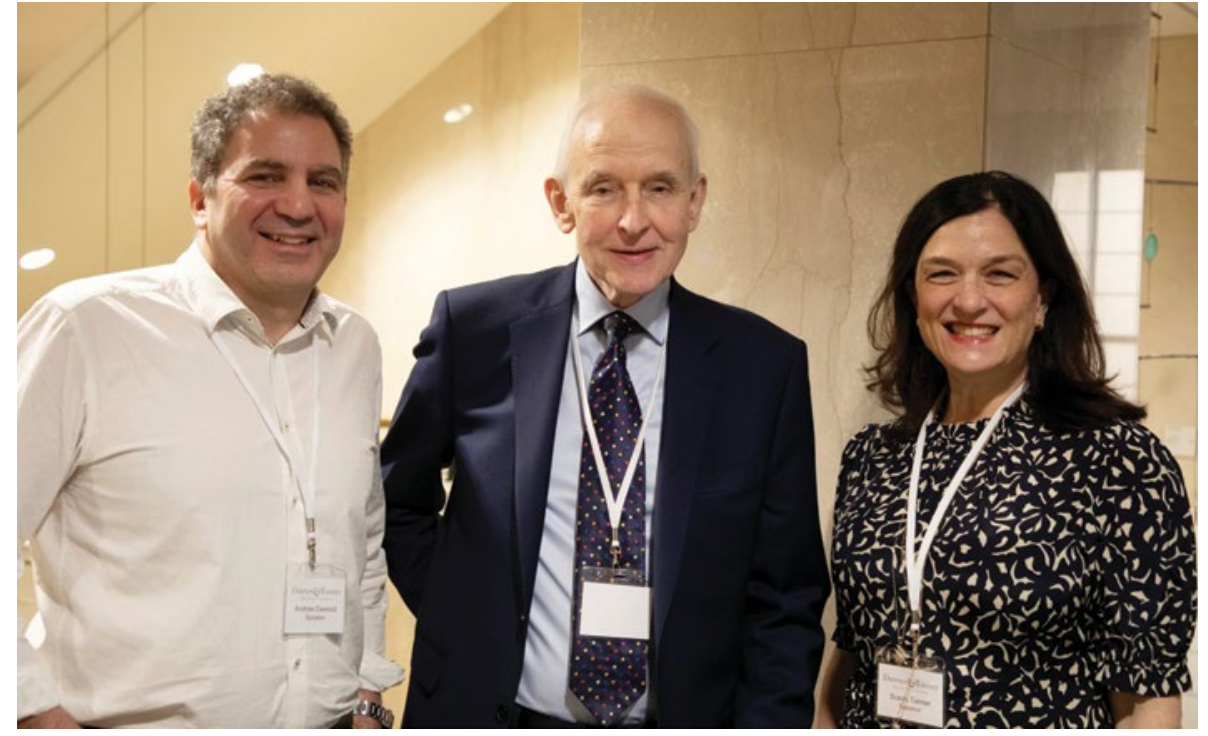

Andrew Dawood (left), Kevin Lewis and Susan Tanner

Dr Tom Bereznicki followed next; Tom has over 30 years' experience in general dental practice treating a wide variety of patients including those with severe restorative problems, where his special interest lies. $\mathrm{He}$ discussed some of the more recent trends in restorative dentistry and outlined their advantages and limitations. From the occlusal aspect there was clarification of working in reorganised and confirmative fashion, but in particular emphasising those cases which do not fall neatly into one or other of these categories.

Following the morning session, the delegates flowed into the main room where sponsors were eagerly waiting to demonstrate new products and introduce services. It was a relaxed and informal atmosphere of dentists networking, sharing opinions and insights, enjoying delicious refreshments and pastries.

After a mid-morning break, Dr Andrew Dawood welcomed delegates back with 'Managing Expectations in Implant Dentistry'. Meeting patient expectations can be one of our greatest challenges in dentistry today. The internet, social media, and reality TV all contribute to a misguided sense of what is possible and can make implant dentistry a particular challenge. Andrew provided a detailed examination, and a comprehensive explanation of what is planned and anticipated before treatment, can make all the difference to the perception of a successful outcome. He reviewed some of the issues that should be discussed, considered, and documented before treatment begins.

This followed into Dr Susan Tanner's talk, 'Exceeding Expectations in Implant Dentistry'. Susan, a specialist prosthodontist, explained that an exceptional result depends upon meticulous planning and the careful application of fundamental prosthodontic principles. Susan explained her protocols which help to ensure that our patient expectations are met or even surpassed.

After a relaxed buffet lunch, delegates were treated to four more lectures. The afternoon began with Dr Zoe Laughlin. Zoe is an artist, engineer, material scientist and broadcaster. She is co-founder and director of The Institute of Making at University College London. Zoe provided a demo-led exploration of materials: the micro will become macro, the inanimate will become animated and the performance of matter revealed. Zoe also talked about her work as the co-founder/director of the Institute of Making at UCL, specific research she has undertaken into The Taste of Materials 
$\varangle$ and the occasional TV project on materials and making.

The session followed with the PechaKucha, and then a lecture from Dr Fiona MacKillop, showing how the periodontal staging and grading system can be implemented effectively into your daily practice, giving examples of how we can make a diagnosis using the new system.
The closing lecture of the day was given by Dr Shanon Patel, consultant endodontist; the aim of this presentation was to give delegates an overview on how to improve the success of treatment by considering planning for success by systemically assessing the patient and the dentition, not just the tooth in question.

Many of the delegates were enthused, and said it was one of the best dental conferences they had attended, gaining new tips and ideas to reflect on, with the added bonus of CPD hours.

All in all, it was a thoroughly informative day with plenty of sound advice and specialist knowledge from the speakers.

The next Dawood and Tanner Study day will be held on 5 February 2021.

\section{SDCEP COVID-19 guidance update}

\author{
The Scottish Dental Clinical Effectiveness \\ Programme (SDCEP) has now modified \\ its guidance on management of \\ commonly presenting oral conditions \\ for use during the COVID-19 pandemic. \\ The new 'Management of Acute Dental \\ Problems during COVID-19 Pandemic' \\ guide is available now on the SDCEP \\ website.
}

This guide is for use by dental teams involved in triaging and managing patients during the current situation. It can be used in conjunction with health board or other local procedures that have been established for managing patients based on their COVID-19 status. Note that this guide is subject to change as new information becomes available. Therefore, please ensure

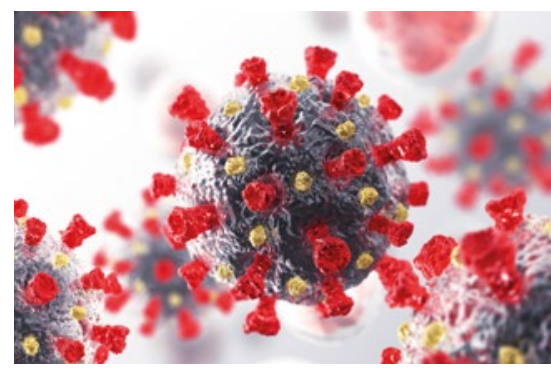

that you are viewing the most recent version by referring to www.sdcep.org.uk.

CONFERENCE REPORT

\section{'So you want to be an orthodontist'}

\section{By Prashanth Narayanan, Trust grade DCT, Level 7 Maxillofacial Department, Derriford Hospital, Plymouth}

The annual 'So you want to an orthodontist' meeting was held at the British Orthodontic Society's (BOS') headquarters in Central London on 31 October 2019.

The meeting was organised by BOS training grades group (TGG) committee representatives Miss Rupal Shah and Mr Nikhil Gogna. There were about 35 delegates attending the meeting all sharing a common passion and showing their keen interest in pursuing a career in orthodontics. It was a busy programme with talks from eminent speakers from varied backgrounds and experiences.

The programme started off with a talk from Ms Helen Tippett, orthodontic consultant, providing a detailed insight of the national recruitment process from a consultant's perspective. This was followed by a candidate's perspective of the national recruitment process - StR2 Ms Libby Richardson having successfully gone through the national recruitment process. These sessions were very informative as delegates could get an idea of what the national recruitment process entails from both perspectives. ${ }^{1}$

Given the cutthroat competition in the field of specialist training, the next session gave brilliant insight into building a robust $\mathrm{CV}$ to help maximise the chances of getting through the national recruitment process. The advice given by Mr Matt Chia, consultant orthodontist, was excellent and he gave delegates wonderful practical tips to help prepare with their application.

This was followed by a talk given by $\mathrm{Mr}$ Owaise Sharif, consultant orthodontist, who gave a summary of the various training programmes in addition to highlighting the importance of a research component as a part of orthodontic registrar training. This was soon followed by talks from current StR3 - Miss Nima Amin and Mr Othan Hameed about what specialty training entails.

The different career prospects in orthodontics after completion of specialist training was summarised by orthodontic specialist Mr John Costello and post CCST (StR5) Miss Rupal Shah. This overview of career prospects in both specialist practice and hospital provided delegates useful information regarding career options and also possibilities for future training as a consultant.

The best part of the day was the informal roundtable discussions held in the afternoon with speakers and candidates who have successfully gone through the recruitment process. This was an informal meeting where different candidates' perspectives were brought to the table and it gave an excellent opportunity for delegates to ask questions and clarify doubts, if any.

To conclude, the day provided the delegates an excellent overview of what a career in orthodontics would involve and I would definitely recommend this for anyone who is interested in specialist orthodontic training now or in the years to come.

Finally, I wish to thank the TGG committee representatives Miss Rupal Shah and Mr Nikhil Gogna for organising this wonderful meeting.

\section{Reference}

1. Richardson L. Conference report: 'So you want to be an orthodontist'. Br Dent J 2018; 224: 125. 